\title{
Phycological Effects of Eutrophication with Fertilizers in Nike Lake, Nigeria
}

\author{
Nkechinyere Onyekewere Nweze*, Ugochi Elizabeth Onyishi \\ Department of Botany, University of Nigeria, Nsukka, Nigeria \\ E-mail: ${ }^{*}$ nknweze@yahoo.com \\ Received September 30, 2011; revised October 30, 2011; accepted November 29, 2011
}

\begin{abstract}
Agriculture around Nike lake uses fertilizers. Fertilizers are known to cause eutrophication of water bodies and associated algal blooms whose consequences may be deleterious to the environment and man. We investigated ex situ to assess the effect of the nutrients on the algal flora and show the impact of farm land runoffs on aquatic environment. The lake water was analysed for initial nitrogen, phosphorus and potassium; and algal content using standard methods. The fertilizer sources used by the farmers-NPK (20:10:10 and 15:15:15); urea and poultry drops, were used in the study to enrich the lake water in concentrations of 0.2 , $0.4,0.6,1.0$ and $2.0 \mathrm{~g} / \mathrm{L}$ in three replicates respectively. A control was set up without the fertilizer sources and the set up was left on a laboratory bench and monitored for 36 days. Cyanobacteria (blue green algae), Chlorophyta (green algae) and Bacillariophyta (diatoms) were encountered and their population increased with time and increase in concentration of fertilizers. The following taxa were encountered-Gloeocapsa, Anabaena, Oscillatoria (blue-green algae); Chlorella, Chlamydomonas, Spirogyra, Closterium, Pediastrum, Ankistrodesmus, Selenastrum, Scenedesmus, Staurastrum (green algae); Pinnularia and Navicula (diatoms) some of which are notable bloom forming species.
\end{abstract}

Keywords: Eutrophication, NPK Fertilizer, Urea, Poultry manure, Cyanobacteria, Chlorophyceae, Bacillariophyceae, Algal Bloom

\section{Introduction}

Nike lake, Enugu, is located between $6^{\circ} 30^{\prime} 19.5^{\prime \prime} \mathrm{N}$ $6^{\circ} 30^{\prime} 22.6^{\prime \prime} \mathrm{N}$ and $7^{\circ} 30^{\prime} 47.2^{\prime \prime} \mathrm{N}-7^{\circ} 30^{\prime} 50.9^{\prime \prime} \mathrm{N}$ at an elevation of about 172.5 meters above sea level. Many anthropogenic activities are carried out around the lake, such as agricultural activities, car wash and block moulding Industries. Also, Nike lake Resort (Protea Hotel) is located beside the lake. These activities have their respective nutrient discharges into the lake. These may lead to the enrichment of the lake and consequent algal bloom that may result [1].

People in Enugu metropolis especially those that live in Abakpa, Nike, Enugu, depend on Nike lake for their water supply especially during the dry season. Moreover, the most vital aspect of their dependence on the lake is for their agricultural production. Telfairia occidentalis, Zea mays, Amaranthus sp, Solanum sp, Ocimum gratisimum and other crops are cultivated around the lake during both wet and dry seasons. Other vegetation around the lake is a mixture of savanna and high forest as documented by Nweze and Domrufus [2]. They include ar- oids, palms, ferns, and grasses which indicate secondary forest vegetation.

Eutrophication is a threat to the water quality of rivers, lakes and reservoirs, hence their classification into oligotrophic, mesotrophic and eutrophic based on level of eutrophication [3]. Cultural eutrophication is a process where a water body changes due to increased reception of nutrients such as nitrogen, potassium and phosphate from anthropogenic activities [1] and also, silicon, potassium, calcium, iron and manganese [3]. These nutrients from the catchment area (allochthonous sources) bring pressure on the receiving environment causing major changes in the ecosystem thereby jeopardizing many beneficiaries of the resources. Such stressed water bodies support a rich algal flora and animal population $[3,4]$. Inorganic nitrogen and phosphorus and iron have been noted as the limiting nutrients in lakes [5,6] This has been demonstrated by laboratory studies by Levine and Schindler [7] using single bloom forming species of algae such as Microcystis aeruginosa.

Studies on the effect of sewage enrichment of lakes 
and deliberate addition of commercial NPK fertilizers on crops or of soy bean and cotton seed meal to lakes subsequently showed that phosphorus was probably controlling productivity in lakes, with nuisance algal blooms occurring where average inorganic phosphorus concentration was $10 \mathrm{~g} / \mathrm{L}$. Nitrogen also plays a role with critical levels around $300 \mathrm{~g} / \mathrm{L}$ inorganic nitrogen. Sawyer [8] noted that agricultural drainage and sewage effluent contain 18 and 5 times respectively of proportion of nitrogen to phosphorus, both having phosphorus levels greater than the minimum needed to stimulate algal growth.

The chief contributors of the nutrient load of freshwaters are artificial fertilizers, animal slurry, sewage and occasionally point sources from food industry [1].

The algal biodiversity of the water as reported in Nweze and Domrufus [2] showed that the metaphyton algal flora was composed of 34 taxa of algae belonging to 5 classes. Some of these, such as Microcystis, Anabaena, Oscillatoria and Euglena are known bloom forming species.

This ex situ investigation was carried out to assess the effect of nutrients contained in inorganic fertilizers and poultry manure on resident algal biodiversity of Nike lake to give insight into their effects on aquatic environment when taken in through runoffs from farm lands.

\section{Materials and Methods}

\subsection{Collection of Samples and Preparation of Apparatus}

Sub-surface water samples were collected from the banks of Nike Lake, Enugu, from about $10 \mathrm{~cm}$ depth, with two $100 \mathrm{~L}$ capacity containers for the enrichment studies in the laboratory. This was to avoid stirring of the mud at the bottom which may contain nutrients.

One hundred milliliters of collected water sample was placed in a plastic jar and fixed with Lugol's iodine after the methods of Bellinger [9]. Three $1 \mathrm{ml}$ aliquots of fixed samples were sedimented in a $1 \mathrm{ml}$ counting chamber for
12 hours and viewed under an a binocular Leica microscope to identify all the algae present in the collected sample. Species were identified using dichotomous keys $[9,10]$ and manuals [11].

Nutrients such as phosphate, nitrate and potassium content of Nike lake water before and after the experiment were determined following the method of APHA [12]. Phosphate (mg/l) and nitrate $(\mu \mathrm{g} / \mathrm{l})$ were determined spectrophotometrically using stannous chloride and phenol disulphonic acid methods respectively in a Spectronic 20 equipment and potassium (mg/l) using atomic absorption/emission spectrophotometer.

Seventy five, $500 \mathrm{ml}$ beakers were washed with soap and rinsed thoroughly with distilled water. Beakers for nutrient enrichment experiments were thereafter rinsed with Nike lake water before use in order to reduce error of dilution.

\subsection{Preparation of Nutrient Dilutions for Enrichment Experiments}

The nutrient sources used were poultry manure $(\mathrm{P})$; Urea (U); NPK fertilizer-20:10:10 (A) and NPK fertilizer15:15:15 (B). The dilutions of various nutrient sources in Nike Lake water were made and labeled as shown in Table 1. Three replicates each of $0.1 \mathrm{~g}, 0.2 \mathrm{~g}, 0.3 \mathrm{~g}, 0.4 \mathrm{~g}$, $0.5 \mathrm{~g}$ and $1.0 \mathrm{~g}$, of these nutrient sources were dissolved in $500 \mathrm{ml}$ aliquots of lake water in 72 beakers for the nutrient experiments. Three $500 \mathrm{ml}$ aliquots of untreated lake water were set up as control in three beakers and labeled $\mathrm{O}_{1}, \mathrm{O}_{2}$ and $\mathrm{O}_{3}$. The set up was left on a laboratory bench near a window for 36 days.

\subsection{Phycological Studies}

Five milliliter aliquots from the treatments were removed at 2-day intervals for phycological studies and stained with 2 drops Lugol's iodine [9]. Algal studies were carried out on three drops from each treatment using a Leica binocular microscope at $\times 40$ objective. Species were

Table 1. Dilutions of various nutrient sources used in enrichment experiments.

\begin{tabular}{|c|c|c|c|c|c|c|c|}
\hline Poultry (P) & Dilution (g/500 mL) & Urea (U) & Dilution $(\mathrm{g} / 500 \mathrm{~mL})$ & $\begin{array}{l}\text { NPK 20:10:10 } \\
\text { (A) }\end{array}$ & Dilution (g/500 mL) & $\begin{array}{l}\text { NPK 15:15:15 } \\
\text { (B) }\end{array}$ & Dilution $(\mathrm{g} / 500 \mathrm{~mL})$ \\
\hline $\mathrm{P}_{2}$ & 0.1 & $\mathrm{U}_{2}$ & 0.1 & $\mathrm{~A}_{2}$ & 0.1 & $\mathrm{~B}_{2}$ & 0.1 \\
\hline $\mathrm{P}_{4}$ & 0.2 & $\mathrm{U}_{4}$ & 0.2 & $\mathrm{~A}_{4}$ & 0.2 & $\mathrm{~B}_{4}$ & 0.2 \\
\hline $\mathrm{P}_{6}$ & 0.3 & $\mathrm{P}_{6}$ & 0.3 & $\mathrm{~A}_{6}$ & 0.3 & $\mathrm{~B}_{6}$ & 0.3 \\
\hline $\mathrm{P}_{8}$ & 0.4 & $\mathrm{P}_{8}$ & 0.4 & $\mathrm{~A}_{8}$ & 0.4 & $\mathrm{~B}_{8}$ & 0.4 \\
\hline $\mathrm{P}_{10}$ & 0.5 & $\mathrm{P}_{10}$ & 0.5 & $\mathrm{~A}_{10}$ & 0.5 & $\mathrm{~B}_{10}$ & 0.5 \\
\hline $\mathrm{P}_{20}$ & 1.0 & $\mathrm{P}_{20}$ & 1.0 & $\mathrm{~A}_{20}$ & 1.0 & $\mathrm{~B}_{20}$ & 1.0 \\
\hline
\end{tabular}


identified using dichotomous keys [9,10] and manuals [11].

\section{Results and Discussion}

A checklist of the algal diversity of Nike lake water used in the experiment is presented in Table 2. Thirty one taxa of algae belonging 4 classes were observed in the Nike lake water used for the experiment. They were: 5 taxa of Cyanobacteria (Gloeocapsa, Microcystis, Oscillatoria (2 taxa) and Anabaena); 21 taxa of Chlorophyceae (Chlorella (2 taxa), Chlamydomonas, Senedesmus (6 taxa), Ankistrodesmus (2 taxa), Oocystis (3 taxa), Pediastrum (2 taxa), Spirogyra (3 taxa), Closterium, and Cladophora); 2 taxa of Euglenophyceae (Euglena and Phacus) and 3 taxa of Bacillariophyceae (Asterionella, Navicula and Pinnularia).

A checklist of algae observed at the end of the experiment are presented in Table 3. There were twenty four (24) taxa. Five (5) of Cyanobacteria/blue green algae represented by Gloeocapsa, Anabaena, Oscillatoria
(2 taxa) and Microcystis); 17 of Chlorophyceae/green algae represented by Chlorella (2 taxa), Chlamydomonas, Scenedesmus (6 taxa), Ankistrodesmus (2 taxa), Pediastrum (2 taxa), Spirogyra (3 taxa), Closterium, Staurastrum and Selenastrum; and 2 of Bacillariophyceae/diatoms represented by Pinnularia and Navicula. Most of these are notable bloom forming species.

The level of growth in the various treatments are presented in Table 4. Total algae were favoured most at 0.2 g/l Urea and NPK 20:10:10; 0.4 g/l poultry manure and $0.6 \mathrm{~g} / \mathrm{l}$ NPK. Higher levels of contamination were toxic to most algae and moreover the blooms had a shading effect on in the water resulting in competition and more respiratory activities by the algae [13].

Bacillariophyceae (diatoms) were mostly favoured by urea. They are common spoilers of boat paints. Poultry manure and NPK fertilizers (20:10:10 and 15:15:15) favoured Cyanobacteria. The fact that poultry manure and NPK fertilizers are commonly used by farmers around the lake exposes the Nike lake and inlets to bloom forming Cyanobacteria with the attendant problems such

Table 2. Checklist of the various classes of algae in Nike Lake used for enrichment experiments.

\begin{tabular}{|c|c|}
\hline Cyanophyceae & Chlorophyceae continued \\
\hline Gloeocapsa nigriscens Naegeli & Oocystis parva West \& West \\
\hline Microcystis aeruginosa Kuetz & O. solitaria Wittrock \\
\hline Oscillatoria formosa Bory & O. elliptica W. West \\
\hline O. granulata Gardner & Pediastrum simplex (Meyeri) Lemm \\
\hline Anabaena ciricinalis var. macrospora (Witt) & P. sculptatum G. M. Smith \\
\hline Chlorophyceae & Spirogyra condensata (Vauch.) Kuetz. \\
\hline Chlorella vulgaris Beyerinck & S. crassa Kuetz \\
\hline Chlorella ellipsoidea Gerneck & S. daedaleoides Curda \\
\hline Chlamydomonas sphagnicola Fritsch \& Takeda & Closterium pusillum Naeg. \\
\hline Senedesmus acuminatus (Lag.) Chodat & Cladophora glomerata (L.) Keutz. \\
\hline S abundans var. longicauda G. M. Smith & Class Euglenophyceae \\
\hline S armatus (Chod.) G. M. Smith & Euglena elastica Presscott. \\
\hline S. bijuga (Turp.) Lagerheim & Phacus caudatus (Heubine) \\
\hline S. incrassatulus var. mononae G. M. Smith & Class Bacillariophyceae \\
\hline S. quadricauda var. quadrispina (Chod.) G. M. Smith & Asterionella formosa Hass. \\
\hline Ankistrodesmus falcatus (Corda) Ralfs & Navicula cuspidata Kuetz \\
\hline A. fractus (West \& West) Brunthaler & Pinnularia nobilis Ehr. \\
\hline
\end{tabular}


Table 3. Checklist of the algae encountered 36 days after treatment with fertilizers.

\begin{tabular}{cc}
\hline Class Cyanophyceae & Chlorophyceae continued \\
Gloeocapsa nigriscens Naegeli & Pediastrum simplex (Meyeri) Lemm. \\
Microcystis aeruginosa Kuetz & P. sculptatum G. M. Smith \\
Oscillatoria formosa Bory & Spirogyra condensate (Vauch.) Kuetz. \\
O. granulata Gardner & S. crassa Kuetz \\
Anabaena ciricinalis var. macrospora (Witt) & S. daedaleoides Czurda \\
Chlorophyceae & Closterium pusillum Naeg. \\
Chlorella vulgaris Beyerinck & Staurastrum Meyen ex Ralfs. \\
C. ellipsoidea Gerneck & Selenastrum Reinsch \\
Chlamydomonas sphagnicola Fritsch \& Takeda & Bacillariophyceae \\
Senedesmus acuminatus (Lag.) Chodat. & Navicula cuspidate Kuetz \\
S. abundans var. longicauda & G. M. Smith \\
S. armatus (Chod.) G. M. Smith & Pinnularia nobilis Ehr. \\
S. bijuga (Turp.) Lagerheim & \\
S. incrassatulus var. mononae G. M. Smith & \\
S. quadricauda var. quadrispina (Chod.) G. M. Smith & \\
Ankistrodesmus falcatus (Corda) Ralfs & \\
A. fractus (West \& West) Brunthaler & \\
\hline &
\end{tabular}

Table 4. Variations in Population of various groups of algae at the end of the investigation (36 WEEKS).

\begin{tabular}{|c|c|c|c|c|}
\hline \multicolumn{5}{|c|}{ Population (individuals/ml) } \\
\hline Concentration & Cyanophyceae & Chlorophyceae & Bacillariophyceae & Total \\
\hline $\begin{array}{c}\text { Control } \\
\text { UREA }\end{array}$ & $162(23.96 \%)$ & $430(63.60 \%)$ & $84(12.98 \%)$ & 676 \\
\hline $0.2 \mathrm{~g} / \mathrm{l}$ & 3200 (34.34\%) & $1260(13.52 \%)$ & $4860(52.15 \%)$ & 9320 \\
\hline $0.4 \mathrm{~g} / \mathrm{l}$ & $2140(52.67 \%)$ & $520(6.62 \%)$ & $3200(40.72 \%)$ & 7860 \\
\hline $0.6 \mathrm{~g} / \mathrm{l}$ & $2820(37.6 \%)$ & $0(0 \%)$ & $4680(62.4 \%)$ & 7500 \\
\hline $0.8 \mathrm{~g} / \mathrm{l}$ & $1780(42.79 \%)$ & $0(0 \%)$ & $2380(57.21 \%)$ & 4160 \\
\hline $2.0 \mathrm{~g} / \mathrm{l}$ & $1760(50.57 \%)$ & $1720(49.43 \%)$ & $0(0 \%)$ & 3480 \\
\hline \multicolumn{5}{|c|}{ POULTRY MANURE } \\
\hline $0.2 \mathrm{~g} / \mathrm{l}$ & 3240 (34.62\%) & $1260(13.46 \%)$ & $4860(51.92 \%)$ & 9360 \\
\hline $0.4 \mathrm{~g} / \mathrm{l}$ & $7720(68.44 \%)$ & $1720(15.25 \%)$ & $1840(16.31 \%)$ & 11280 \\
\hline $0.6 \mathrm{~g} / \mathrm{l}$ & $4660(86.62 \%)$ & $0(0 \%)$ & $720(13.38 \%)$ & 5380 \\
\hline $0.8 \mathrm{~g} / \mathrm{l}$ & $4640(90.63 \%)$ & $0(0 \%)$ & $480(9.37 \%)$ & 5120 \\
\hline $1.0 \mathrm{~g} / \mathrm{l}$ & $4600(81.56 \%)$ & $100(1.77 \%)$ & $940(16.67 \%)$ & 5640 \\
\hline $0.2 \mathrm{~g} / 1$ & 4960 (25.20\%) & 2460 (12.5\%) & $12260(62.30 \%)$ & 19680 \\
\hline $0.4 \mathrm{~g} / \mathrm{l}$ & $7940(48.36 \%)$ & $1560(9.50 \%)$ & $6920(42.13 \%)$ & 16420 \\
\hline $0.6 \mathrm{~g} / \mathrm{l}$ & $8320(63.41 \%)$ & $0(0 \%)$ & $4800(36.59 \%)$ & 13120 \\
\hline $0.8 \mathrm{~g} / \mathrm{l}$ & $9100(63.41 \%)$ & $0(0 \%)$ & 5340 (36.98\%) & 14440 \\
\hline $1.0 \mathrm{~g} / \mathrm{l}$ & $9980(96.33 \%)$ & $140(1.35 \%)$ & $240(2.32 \%)$ & 10380 \\
\hline $2.0 \mathrm{~g} / 1$ & $11980(79.97 \%)$ & $2820(18.83 \%)$ & $180(1.20 \%)$ & 14980 \\
\hline \multicolumn{5}{|c|}{ NPK 15:15:15 } \\
\hline $0.2 \mathrm{~g} / \mathrm{l}$ & 6840(98.84\%) & $80(1.16 \%)$ & $0(0 \%)$ & 6920 \\
\hline $0.4 \mathrm{~g} / \mathrm{l}$ & $7300(94.46 \%)$ & $40(0.54 \%)$ & $0(0 \%)$ & 7340 \\
\hline $0.6 \mathrm{~g} / \mathrm{l}$ & $6900(41.42 \%)$ & $60(0.36 \%)$ & $9700(58.22 \%)$ & 16660 \\
\hline $0.8 \mathrm{~g} / \mathrm{l}$ & $7380(52.12 \%)$ & $40(0.28 \%)$ & $6820(48.16 \%)$ & 14160 \\
\hline $1.0 \mathrm{~g} / \mathrm{l}$ & $8520(64.25 \%)$ & $0(0 \%)$ & 4740 (35.75\%) & 13260 \\
\hline $2.0 \mathrm{~g} / \mathrm{l}$ & $5560(100 \%)$ & $0(0 \%)$ & $0(0 \%)$ & 9560 \\
\hline
\end{tabular}


as depletion of oxygen in water causing anoxia which may lead to suffocation of aquatic flora and fauna; unpleasant odours or foul smell that render the water unsuitable for recreation; blocking of filters of water treatment plants and industrial plants that use water for cooling of turbines and off flavor problems in fish. Moreover, Cyanobacteria blooms (Microcystis and Anabaena) secrete toxins (microcystins, saxitoxin, nodularin) that are carcinogenic, neurotoxic, hepatotoxic, tetratoxic; may cause renal failure (during dialysis), gastroenteritis, diarrhea and skin irritation to swimmers [14-16].

Chlorophyceae were not dominant in any of the dilutions with the various contaminants suggesting that they were not favoured by the nutrients because they are mostly clean water algae. Moreover the bloom formers Cyanobacteria may have hampered their growth through allelopathic action as noted by Lee [16].

\section{Conclusions}

Results from this study indicate that indiscriminate use of fertilizers around Nike lake may lead to Cyanophycean blooms and ecological disaster if not controlled. This may jeopardize the recreational use of lake by visiting tourists to the resort.

\section{References}

[1] V. A. Elizarova, "The Effects of Near-Bottom Water in the Rybinsk Reservoir on Planktonic Diatoms,” Maintaining the Environment, Vol. 1, 2004, pp. 35-37.

[2] N. O. Nweze and N. A. Domrufus, "Limnological Studies on Nike Lake, Enugu, Enugu State-The Metaphyton and Some Physic-Chemical Aspects," Nigerian Journal of Botany, Vol. 19, No. 2, 2006, pp. 396-404.

[3] D. Harper, "Eutrophication of Freshwaters: Principles, Problems and Restoration,” Chapman and Hall, London, 1992, p. 327.

[4] A. D. Boney, "Phytoplankton,” Chapman and Hall, New York, 1989, p. 118.
[5] P. H. Graham, "Phytoplankton Ecology: Structure, Function and Fluctuation,” Chapman and Hall, London, 1986, p. 384.

[6] A. E. Thomas, "The progress of Eutrophication in Central European Lakes,” In: Eutrophication: Causes, Consequences, Correctives, National Academy of Sciences, Washington DC, 1996, pp. 17-28.

[7] S. N. Levine and D. N. Schindler, "Phosphorus, Nitrogen and Carbon Dynamics of Experimental Lake 303 during Recovery from Eutrophication," Canadian Journal of Fisheries and Aquatic Sciences, Vol. 46, No. 1, 1989, pp. 2 10. doi:10.1139/f89-001

[8] C. N. Sawyer, "Fertilization of Lakes by Agriculture and Industrial Drainage,” New England Water Works Association, Vol. 69, 1986, pp. 109-127.

[9] E. G. Bellinger, “A Key to Common Algae. Freshwater, Estuarine and Some Coastal Species,” 4th Edition, Institute of Water and Environment, London, 1992, p. 138.

[10] G. W. Prescott, "How to know the Freshwater Algae," W.M.C. Company Publishers, Iowa, 1964, p. 272.

[11] H. Belcher and E. Swale, "A Beginners Guide to Freshwater Algae,” Her Majesty’s Stationery Office, London, 1976, p. 47.

[12] American Public Health Association (APHA), "Standard Methods for Examination of Water, Sewage and Waste Water,” American Public Health, Washington DC, 1985, p. 769 .

[13] T. Morris, "Harmful Algal Blooms in North Carolina: Blue Greens and Human Health,” Division of Public Health, North Carolina Department of Health and Human Services, 2003, p. 7.

[14] M. W. Brunson, C. Greg Lutz and R. M. Durborow, "Algae Blooms in Commercial Fish Production Ponds," Southern Regional Aquaculture Center (SRAC) Publication No. 466, 1994. http://aquanic.org/publicat/usda_rac/efs/srac/466ff.pdf

[15] World Health Organisation (WHO), "Water-Related Diseases,” World Water Day 2001 Publication, WHO, Geneva, 2007. http://www.who.int/en

[16] R. E. Lee, "Phycology," 4th Edition, Cambridge University Press, New York, 2008, p. 645. 